\title{
Rat liver responsiveness to gluconeogenic substrates during insulin-induced hypoglycemia
}

H.M. de Souza ${ }^{1}$, G.R. Borba-M urad ${ }^{1}$, R.B. Ceddia², R. Curi', M. Vardanega-Peicher ${ }^{4}$ and R.B. Bazotte 4

\section{Correspondence}

R.B. Bazotte

Departamento de Farmácia e

Farmacologia, UEM

87020-900 M aringá, PR

Brasil

Fax: +55-44-263-6231

E-mail: rbbazotte@uem.br

Research supported by PRONEX (No. 168/97), CN Pq and CAPES. Publication supported by FAPESP.

Received October 4, 2000 Accepted March 20, 2001

\author{
1Departamento de Ciências Fisiológicas, \\ Universidade Estadual de Londrina, Londrina, PR, Brasil \\ ²Departamento de Educação Física, \\ Universidade Federal Fluminense, Niterói, RJ, Brasil \\ ${ }^{3}$ Departamento de Fisiologia e Biofísica, \\ Universidade de São Paulo, São Paulo, SP, Brasil \\ ${ }^{4}$ Departamento de Farmácia e Farmacologia, \\ Universidade Estadual de Maringá, M aringá, PR, Brasil
}

\section{Abstract}

Hepatic responsiveness to gluconeogenic substrates during insulininduced hypoglycemia was investigated. For this purpose, livers were perfused with a saturating concentration of $2 \mathrm{mM}$ glycerol, $5 \mathrm{mM} \mathrm{L}-$ alanine or $5 \mathrm{mM}$ L-glutamine as gluconeogenic substrates. All experiments were performed $1 \mathrm{~h}$ after an ip injection of saline (CN group) or $1 \mathrm{IU} / \mathrm{kg}$ of insulin (IN group). The IN group showed higher $(\mathrm{P}<0.05)$ hepatic glucose production from glycerol, L-alanine and L-glutamine and higher $(\mathrm{P}<0.05)$ production of L-lactate, pyruvate and urea from L-alanine and L-glutamine. In addition, ip injection of $100 \mathrm{mg} / \mathrm{kg}$ glycerol, L-alanine and L-glutamine promoted glucose recovery. The results indicate that the hepatic capacity to produce glucose from gluconeogenic precursors was increased during insulin-induced hypoglycemia.

\section{Introduction}

Although insulin inhibits key enzymes of gluconeogenesis (1) and the mobilization of gluconeogenic substrates to the liver (2-5), it is well established that insulin-induced hypoglycemia (IIH) provokes the release of hormones (6-11), which stimulate hepatic gluconeogenesis (11-16).

Although the participation of hepatic gluconeogenesis in glucose recovery has been extensively investigated, relatively little is known about the hepatic responsiveness to gluconeogenic substrates during IIH. Thus, it is not clear whether the higher hepatic glucose production during IIH can be attributed to the improved capacity of the liver to produce glucose and/or to the enhanced availability of gluconeogenic substrates, since the concentration of glucose precursors increases $(12,17,18)$ or decreases $(8,19-21)$ during $\mathrm{IIH}$, depending on the experimental condition. To clarify this question and to overcome the limitations of in vivo experiments, we employed isolated liver from fasted rats which received a saturating concentration of gluconeogenic substrates at constant flow. This experimental approach eliminates the influence of hepatic glycogen catabolism, changes in hepatic blood flow, and the 
variability of blood glucose precursors (2225).

Moreover, if the hepatic responsiveness to gluconeogenic substrates is augmented during $\mathrm{IIH}$, the possibility of obtaining glucose recovery by the administration of glucose precursors should be considered. For this reason, we also investigated the effect of the administration of gluconeogenic precursors on glycemia during IIH.

\section{Material and Methods}

Male Wistar rats weighing $200 \mathrm{~g}$, aged around 7 weeks and submitted to $6 \mathrm{~h}$ of food deprivation were employed.

All experiments were initiated at 2:00 pm to minimize circadian variations. At that time, $1 \mathrm{IU} / \mathrm{kg}$ of regular insulin (hypoglycemic rats, IN group) or saline (control rats, $\mathrm{CN}$ group) was administered intraperitoneally (ip). Since hypoglycemia has been demonstrated to occur $1 \mathrm{~h}$ after insulin administration (23-25), this time was selected for all experiments.

Isolated perfused livers were used as described previously $(24,25)$. The major advantage of using an isolated organ such as the liver is that the effects measured are attributable directly to the liver and no extrahepatic influence interferes with the results. Even though some techniques remove the liver from the animal, we prefer to leave it in situ. An advantage of leaving the liver in situ is the continuous secretion of bile into the intestine.

Thus, $1 \mathrm{~h}$ after the administration of insulin (Neosulin ${ }^{\circledR}$, Biobrás, Montes Claros, MG, Brazil) or saline, all rats were anesthetized $i p$ with pentobarbital sodium $(40 \mathrm{mg} / \mathrm{kg})$. After laparotomy, blood was collected from the vena cava for the measurement of glucose (26), glycerol (27), L-alanine (28) and Lglutamine (29).

After blood collection, the livers were perfused in situ through the portal vein. Since a proper supply of oxygen is crucial, the liver received a perfusion fluid saturated with oxygen $\left(95 \% \mathrm{O}_{2} / 5 \% \mathrm{CO}_{2}\right)$ at a high flow rate $(4 \mathrm{ml} / \mathrm{g})$. The viability of the liver during the perfusion was indicated by the absence of any leaking and/or tissue swelling.

To evaluate the maximal capacity of the liver to produce glucose, L-lactate, pyruvate and urea from saturating concentrations of 2 $\mathrm{mM}$ glycerol, $5 \mathrm{mM}$ L-alanine or $5 \mathrm{mM} \mathrm{L}$ glutamine, each substrate was infused between the 10th and 30th min of the perfusion period, followed by a period of post-infusion (20 $\mathrm{min}$ ) to allow the return to basal levels. Samples of the effluent perfusion fluid were collected at 2-min intervals for a total collection period of $30 \mathrm{~min}$ and analyzed for D-glucose, L-lactate, pyruvate and urea. Thus, the maximal hepatic capacity to produce glucose, L-lactate, pyruvate and urea was measured as the difference between the rates of these products released during (10-30 $\mathrm{min})$ and before (0-10 $\mathrm{min})$ substrate infusion. The differences permitted us to obtain and compare the areas under the curves (AUC) for control and hypoglycemic rats.

D-glucose was measured by the glucoseoxidase method (26). L-Lactate (30) is oxidized to pyruvate by nicotinamide adenine dinucleotide (NAD) in the enzymatic reaction catalyzed by lactate dehydrogenase (LDH). The reduction of NAD is proportional to the substrate converted and is measured spectrophotometrically at $340 \mathrm{~nm}$. Similarly, pyruvate (31) is reduced to L-lactate by NADH in the enzymatic reaction catalyzed by $\mathrm{LDH}$. The oxidation of NADH is proportional to the substrate converted and is measured spectrophotometrically at $340 \mathrm{~nm}$. Additionally, urea (32) was measured using urease. The ammonia resulting from enzymatic hydrolysis of urea reacts with phenol and hypochlorite, producing the blue dye indophenol, which is proportional to urea concentration.

To investigate the effect of the adminis- 
tration of gluconeogenic substrates on glucose recovery, $100 \mathrm{mg} / \mathrm{kg}$ glycerol, $100 \mathrm{mg} /$ $\mathrm{kg} \mathrm{L}$-alanine or $100 \mathrm{mg} / \mathrm{kg}$ L-glutamine was injected ip 30 min after insulin administration. In these experiments two control groups which received saline or glucose $(100 \mathrm{mg} /$ $\mathrm{kg}$ ) were employed. Glycemia was measured in blood samples collected by decapitation $30 \mathrm{~min}$ later, i.e., $60 \mathrm{~min}$ after insulin injection.

The computer program GraphPad Prism (version 2.0) was used to calculate the AUC, expressed as $\mu \mathrm{mol} / \mathrm{g}$. Statistical analyses were performed using the unpaired Student $t$-test and the Primer Biostatistics program. A 95\% level of confidence $(\mathrm{P}<0.05)$ was accepted for all comparisons. Results are reported as means \pm SEM.

\section{Results}

Insulin administration decreased $(\mathrm{P}<0.05)$ the blood concentration of glucose and glycerol. However, blood levels of L-alanine and L-glutamine were similar to those observed in the control animals (Table 1).

The maximal hepatic capacity to produce glucose was first evaluated for glycerol. As shown in Figure 1, the infusion of a saturating concentration of glycerol promoted a rapid increase in hepatic glucose production for both animal groups (IN and $\mathrm{CN}$ ). The AUC values calculated by subtracting the basal rates indicated a more intense $(\mathrm{P}<0.05)$ activation of glucose production by glycerol for the IN group. Similarly, livers from the IN group showed higher $(\mathrm{P}<0.05)$ production of glucose, L-lactate, pyruvate and urea during the infusion of L-alanine (Figure 2) and L-glutamine (Figure 3) than the $\mathrm{CN}$ group.

Moreover, the effect of $i p$ administration of $100 \mathrm{mg} / \mathrm{kg}$ glycerol, $100 \mathrm{mg} / \mathrm{kg}$ L-alanine or $100 \mathrm{mg} / \mathrm{kg}$ L-glutamine on glycemia during IIH was investigated. As shown in Figure 4 , rats which received an ip injection of glycerol, L-alanine or L-glutamine had higher glycemia $(\mathrm{P}<0.05)$ than rats which received saline or glucose.

\section{Discussion}

Perfused livers from fasted rats produce negligible amounts of glucose in the absence of gluconeogenic precursors. The addition of glycerol, L-alanine or L-glutamine increases the rate of glucose production in proportion to the amount of the glucose precursor until a saturating concentration is reached (data not shown). Thus, by using a saturating concentration of gluconeogenic precursors it was possible to measure the maximal capacity of the liver to produce glucose from specific substrates $(24,25)$.

On the other hand, the most common substrates for gluconeogenesis, such as Llactate and L-alanine, cross the liver cell

Table 1. Blood levels of glucose, glycerol, L-alanine and L-glutamine (in mM) 60 min after saline (CN group) or insulin (IN group) administration.

\begin{tabular}{lll}
\hline & \multicolumn{1}{c}{ CN } & \multicolumn{1}{c}{ IN } \\
\hline Glucose & $6.95 \pm 0.320$ & $2.82 \pm 0.26^{*}$ \\
Glycerol & $0.057 \pm 0.003$ & $0.045 \pm 0.002^{*}$ \\
L-Alanine & $0.19 \pm 0.01$ & $0.21 \pm 0.01$ \\
L-Glutamine & $0.90 \pm 0.04$ & $1.05 \pm 0.05$
\end{tabular}

Data are reported as means \pm SEM $(\mathrm{N}=10)$. $* \mathrm{P}<0.05$ vs $\mathrm{CN}$ group (unpaired Student t-test).

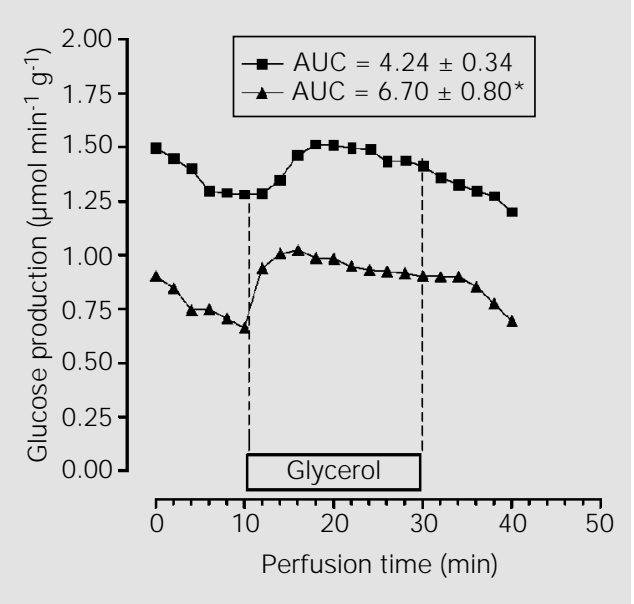

Figure 1. Effect of glycerol (2 $\mathrm{mM})$ on glucose production in rats which received saline (CN group, squares) or $1 \mathrm{IU} / \mathrm{kg}$ of regular insulin (IN group, triangles). Data are reported as the mean of 5 individual liver perfusion experiments. The livers were perfused as described in Material and Methods. AUC $=$ area under the curve. $* \mathrm{P}<0.05$ vs saline (unpaired Student ttest). 
Figure 2. Effect of L-alanine (5 $\mathrm{mM}$ ) on glucose (panel A), L-lactate (panel B), pyruvate (panel C) and urea production (panel $\mathrm{D}$ ) in rats which received saline (CN group, squares) or $1 \mathrm{IU} / \mathrm{kg}$ of regular insulin (IN group, triangles). Data are reported as the mean of 4 individual liver perfusion experiments. The livers were perfused as described in Material and Methods. AUC = area under the curve. $* \mathrm{P}<0.05$ vs saline (unpaired Student ttest). membrane and are then converted to pyruvate. From the cytosol, pyruvate enters the mitochondria where it is carboxylated and then leaves the mitochondria as aspartate or malate. In the cytosol these compounds are converted to oxaloacetate, then to phosphoenolpyruvate and after various steps they are converted to glucose by microsomal glucose-6-phosphatase and released from the hepatocyte. Since this complex pathway depends on oxygen supply and several cellular compartments (plasma membrane, cytosol, mitochondria and microsomal fraction), the production of glucose, L-lactate and pyruvate from L-alanine can be used as a marker of the integrity of this metabolic pathway. An absence of glucose production and/or a high L-lactate/pyruvate ratio indicate low viability and/or poor oxygenation. Thus, Lalanine works as a good marker of the quality of the organ preparation.

Therefore, by using a saturating concentration of $2 \mathrm{mM}$ glycerol, $5 \mathrm{mM}$ L-alanine or $5 \mathrm{mM}$ L-glutamine we obtained data compatible with the view that the ability of the liver to produce glucose increases during $\mathrm{IIH}$. This conclusion is based on the observation that livers from hypoglycemic rats show higher glucose production from glycerol (Figure 1), L-alanine (Figure 2A) and L-glutamine (Figure 3A). Part of these results can be explained by the fact that there is an increased release of counterregulatory hormones during IIH (6-10) which antagonize
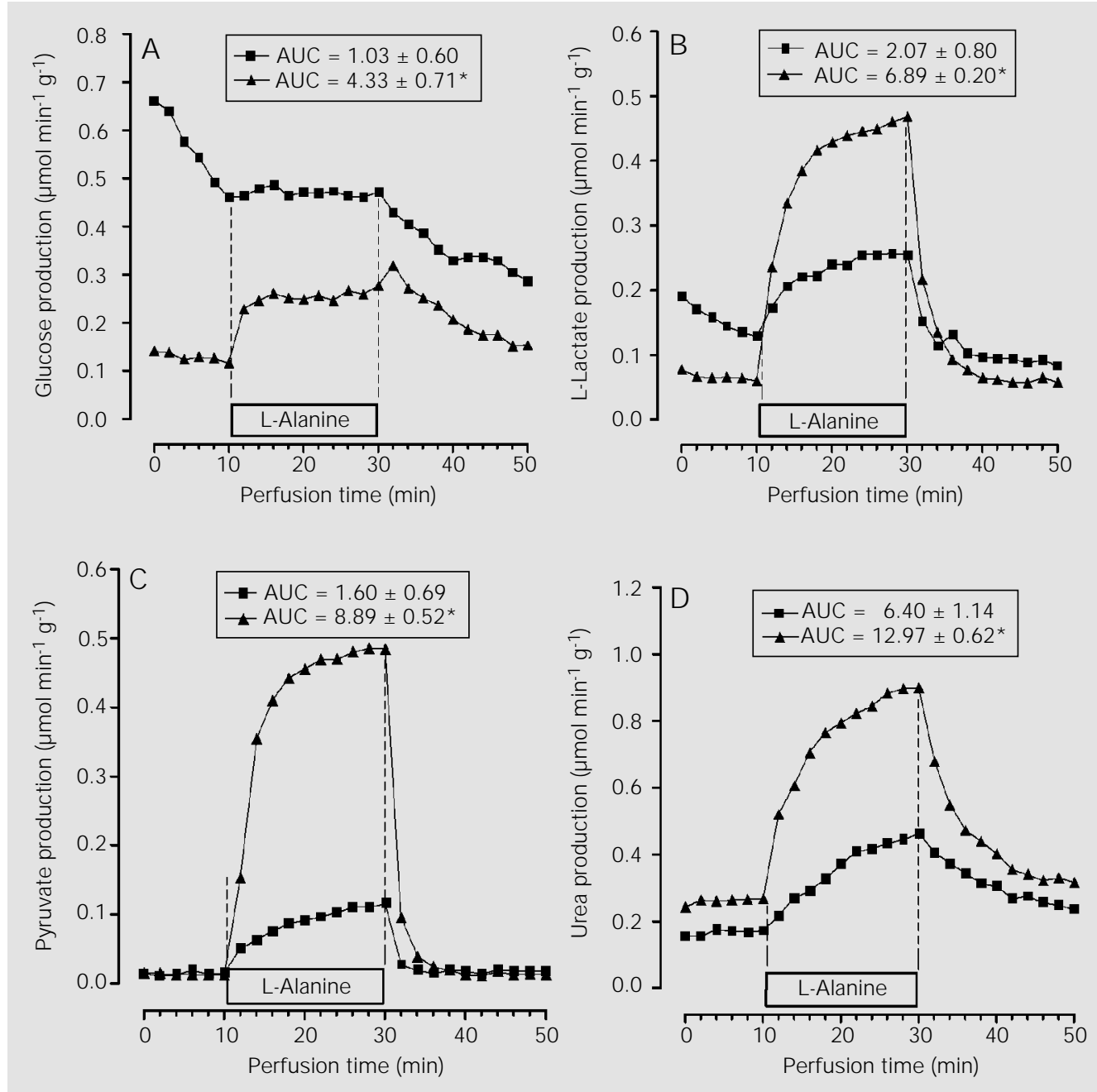
the effects of insulin on the gluconeogenesis key enzymes $(1,33)$, i.e., pyruvate kinase and phosphoenolpyruvate carboxykinase. However, the participation of these enzymes is not the whole story since substrates that enter the gluconeogenic pathway at the triose phosphate step (glycerol) were similarly affected by IIH.

The higher hepatic glucose production from L-alanine exhibited by the IN group was probably the result of the increased catabolism of this amino acid, inferred by the higher $(\mathrm{P}<0.05)$ urea production (Figure $2 \mathrm{D})$ which favored the generation of gluconeogenic intermediaries in the liver. In agreement with this observation, the IN group showed higher $(\mathrm{P}<0.05)$ hepatic production of L-lactate (Figure 2B) and pyruvate (Figure $2 \mathrm{C}$ ) during L-alanine infusion. Consequently, the increased availability of L-lactate and pyruvate in the hepatocyte favored gluconeogenesis $(34,35)$ and helped to explain the higher hepatic glucose production showed by the IN group during the L-alanine infusion (Figure 2A).

Livers from the IN group also showed higher $(\mathrm{P}<0.05)$ hepatic production of $\mathrm{L}$ lactate, pyruvate and urea from L-glutamine (Figure 3). The higher production of urea (Figure 3D, $\mathrm{P}<0.05$ ) was probably due to the increased catabolism of L-glutamine, which contributed to the higher capacity of glucose production. On the other hand, since L-glutamine is not a precursor of pyruvate or L-
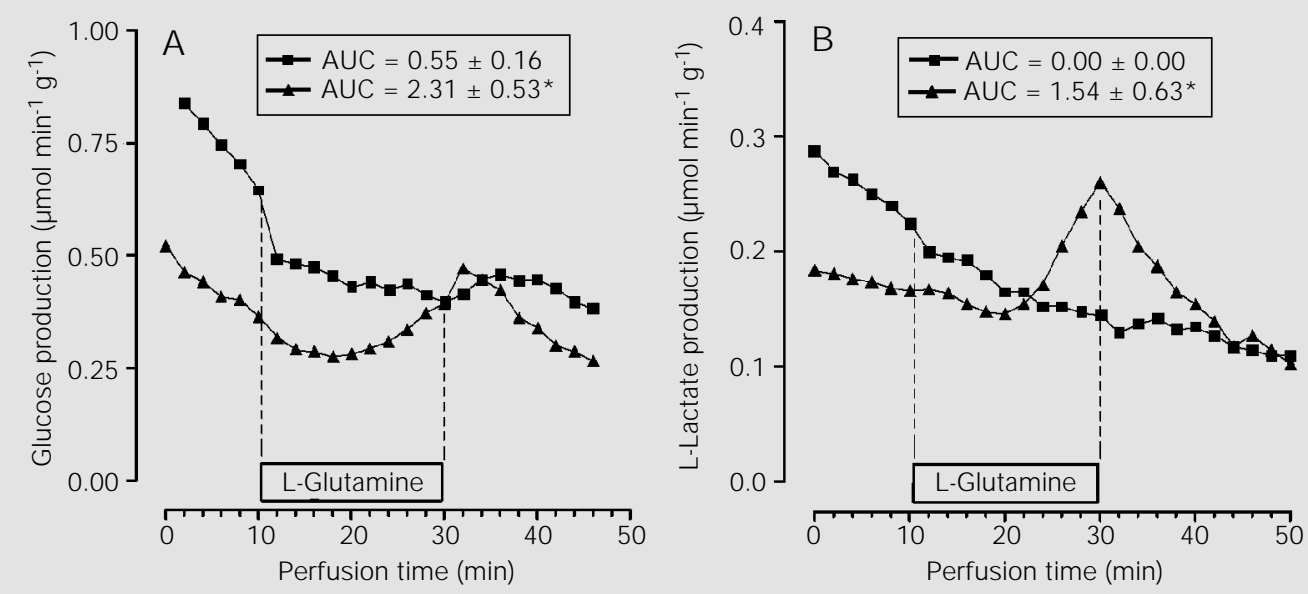

Figure 3. Effect of L-glutamine (5 mM) on glucose (panel A), Llactate (panel B), pyruvate (panel C) and urea production (panel D) in rats which received saline $(\mathrm{CN}$ group, squares) or $1 \mathrm{IU} / \mathrm{kg}$ of regular insulin (IN group, triangles). Data are reported as the mean of 4 individual liver perfusion experiments. The livers were perfused as described in Material and Methods. AUC = area under the curve. $* P<0.05$ vs saline (unpaired Student ttest).
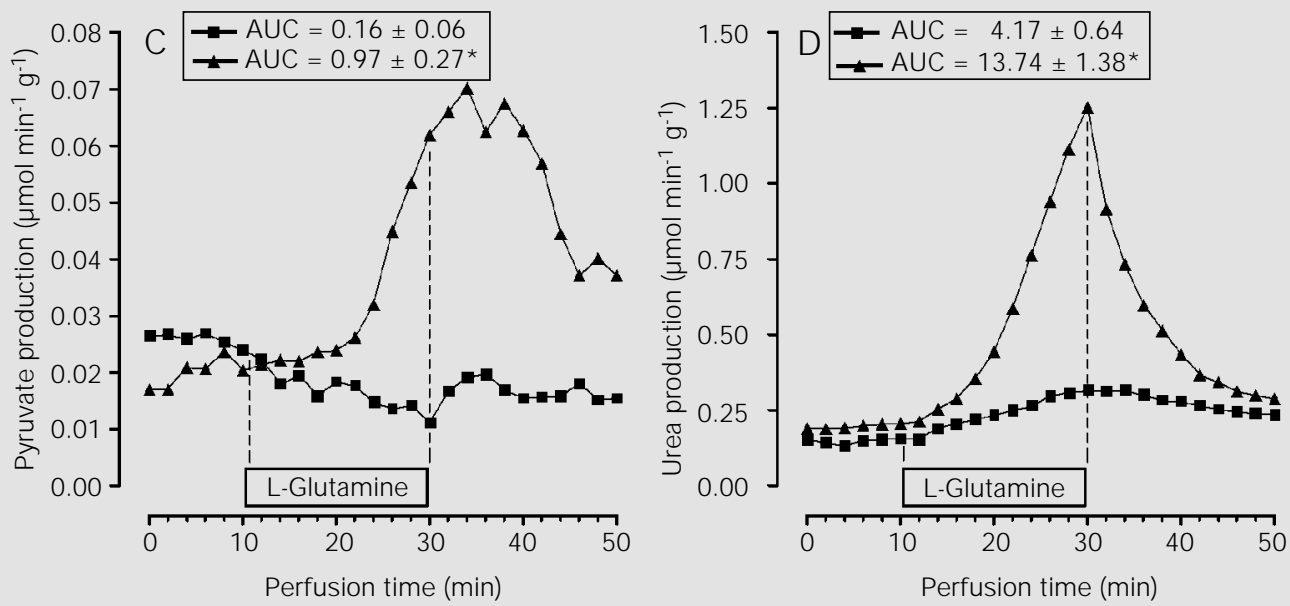
Figure 4. Effect of saline (C), glucose $(\mathrm{Gl})$, glycerol $(\mathrm{G})$, L-alanine (A) and L-glutamine (Gt) on glycemia. All substances $(100 \mathrm{mg} /$ $\mathrm{kg}$, ip) were administered $30 \mathrm{~min}$ after insulin injection and glycemia was measured 60 min after insulin administration. Data are reported as means \pm SEM of 7-9 rats. $* \mathrm{P}<0.05$ vs $\mathrm{C}$ group (unpaired Student t-test).

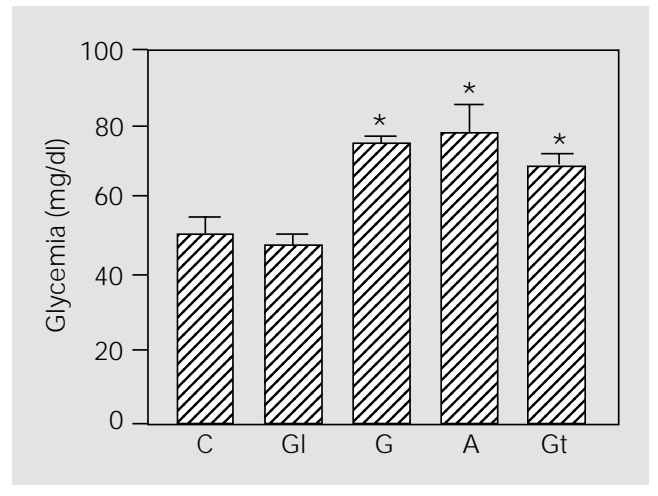

lactate directly and because the kinetics and magnitude of L-lactate and pyruvate production followed the kinetics of glucose production (Figure 3A), it is possible that the pyruvate and L-lactate produced during L-glutamine infusion came from glycolysis. In addition, we observed a delay in the conversion of L-glutamine to glucose, pyruvate, L-lactate and urea (Figure 3), an effect that may be attributed to the slow activation of hepatic glutaminase $(36,37)$.

Since during IIH, blood glucose precursors investigated were decreased or maintained (Table 1) and the hepatic capacity to produce glucose from these substrates was increased (Figures 1, 2, and 3), we determined whether the ip injection of these precursors (glycerol, L-alanine and L-glutamine, each $100 \mathrm{mg} / \mathrm{kg}$ ) could promote glucose recovery.

As illustrated in Figure 4, rats that received glycerol, L-alanine or L-glutamine 30 min after insulin administration showed higher $(\mathrm{P}<0.05)$ glycemia than the controls. Moreover, the absence of glycemia recovery during glucose administration, in contrast to gluconeogenic substrate injection, was unexpected.

Thus, we conclude that the administration of gluconeogenic precursors during $\mathrm{IIH}$ promoted glucose recovery due to the increased hepatic responsiveness to gluconeogenic substrates. Finally, our previous results $(24,25)$, taken together with those of the present study, suggest the possibility of the administration of glucose precursors for the treatment of $\mathrm{IIH}$, particularly in conditions in which therapy with glucagon is not effective.

\section{References}

1. Pilks SJ \& Granner DK (1992). Molecular physiology of the regulation of hepatic gluconeogenesis and glycolysis. Annual Review of Physiology, 54: 885-909.

2. Nurjhan N, Campbell PJ, Kennedy FP, Miles J M \& Gerich J E (1986). Insulin doseresponse characteristics for suppression of glycerol release and conversion to glucose in humans. Diabetes, 35: 1326-1331.

3. Freyse EJ , Fischer U, Albrecht G, Marx S $\&$ Keilacker H (1987). The effect of prehepatic insulin administration on alanine flux rates in diabetic dogs. Diabetologia, 30: 402-408.

4. Lewis GF, Zinman B, Groenewoud Y, Vranic M \& Giacca A (1996). Hepatic glucose production is regulated both by direct hepatic and extrahepatic effects of insulin in humans. Diabetes, 45: 454-462.

5. Sindelar DK, Chu CA, Rohlie M, Neal DW, Swift LL \& Cherrington AD (1997). The role of fatty acids in mediating the effects of peripheral insulin on hepatic glucose production in the conscious dog. Diabetes, 46: 187-196.

6. Rizza RA, Cryer PE \& Gerich JE (1979). Role of glucagon, catecholamines, and growth hormone in human glucose counterregulation. Effects of somatostatin and combined alfa- and beta-adrenergic blockade on plasma glucose recovery and glucose flux rates after insulin-induced hypoglycemia. J ournal of Clinical Investigation, 64: 62-71.

7. Fanelli CG, De Feo P, Porcellat IF, Perriello G, Torlone E, Santeusanio F, Brunetti P \& Bolli GB (1992). Adrenergic mechanisms contribute to the late phase of hypoglycemic glucose counterregulation in humans by stimulating lipolysis. J ournal of Clinical Investigation, 89: 2005-2013.

8. Nair KS, Welle SL \& Tito J (1990). Effect of plasma amino acid replacement on glucagon and substrate responses to insulininduced hypoglycemia in humans. Diabetes, 39: 376-382.
9. Davis SN, Dobbins R, Tarumi C, J acobs J , Neal D \& Cherrington AD (1995). Paradoxal insulin-induced increase in gluconeogenesis in response to prolonged hypoglycemia in conscious dogs. American J ournal of Physiology, 268 (Part 1): E521E531.

10. Lewis GF, Carpentier A, Bilinski D, Giacca A \& Vranic M (1999). Counterregulatory response to hypoglycemia differs according to the insulin delivery route, but does not affect glucose production in normal humans. J ournal of Clinical Endocrinology and Metabolism, 84: 1037-1046.

11. Caprio S, Saccà L, Tamborlane WV \& Sherwin RS (1988). Relationship between changes in glucose production and gluconeogenesis during mild hypoglycemia in humans. Metabolism, 37: 707-710.

12. Frizzell RT, Hendrick GK, Biggers DW, Lacy DB, Donahue DP, Green DR, Carr RK, Williams PE, Stevenson RW \& Cherrington $A D$ (1988). Role of gluconeogene- 
sis in sustaining glucose production during hypoglycemia caused by continuous insulin infusion in conscious dogs. Diabetes, 37: 749-759.

13. Lecavalier L, Bolli G, Cryer P \& Gerich J (1989). Contributions of gluconeogenesis and glycogenolysis during glucose counterregulation in normal humans. American J ournal of Physiology, 256: E844-E851.

14. Garber AJ , Cryer PE, Santiago J V, Haymond MW, Pagliara A \& Kipnis DM (1976). The role of adrenergic mechanisms in the substrate and hormonal response to insulin-induced hypoglycemia in man. J ournal of Clinical Investigation, 58: 7-15.

15. Clarke WL, Santiago J V, Thomas L, BenGalim E, Haymond MW \& Cryer PE (1979). Adrenergic mechanisms in recovery from hypoglycemia in man: adrenergic blockade. American J ournal of Physiology, 236: E147-E152.

16. Cryer P (1993). Glucose counterregulation: prevention and correction of hypoglycemia in humans. American J ournal of Physiology, 264: E149-E155.

17. Hourani H, Lacy B, Eltayeb K \& Abumrad NN (1992). The role of central nervous system in modulating glucose and protein metabolism during insulin-induced hypoglycemia. Brain Research, 587: 276284.

18. Fanelli C, Calderone S, Epifano L, De Vincenzo A, Modarelli F, Pampanelli S, Perriello G, De Feo P, Brunetti P, Gerich J E \& Bolli GB (1993). Demonstration of a critical role for free fatty acids in mediating counterregulatory stimulation of gluconeogenesis and suppression of glucose utilization in humans. J ournal of Clinical Investigation, 92: 1617-1622.

19. De Feo P, Perriello G, Torlone E, Ventura MM, Fanelli C, Santeusanio F, Brunetti P, Gerich J E \& Bolli GB (1989). Contribution of cortisol to glucose counterregulation in humans. American J ournal of Physiology, 257: E35-E42.

20. De Feo P, Perriello G, De Cosmo S, Ventura MM, Campbell PJ, Brunetti P, Gerich J E \& Bolli GB (1986). Comparison of glucose counterregulation during short- term and prolonged hypoglycemia in normal humans. Diabetes, 35: 563-569.

21. De Feo P, Perriello G, Santeusanio F, Brunetti P, Bolli G \& Haymond MN (1992). Differential effects of insulin-induced hypoglycemia on plasma branched-chain and non-branched-chain amino acid concentration in humans. Diabetes and Metabolism, 18: 277-282.

22. Ceddia RB, Lopes G, Souza HM, BorbaMurad GR, William J r WN, Bazotte RB \& Curi R (1999). Acute effects of leptin on glucose metabolism of in situ rat perfused livers and isolated hepatocytes. International J ournal of Obesity, 23: 1207-1212.

23. Souza HM, Hell NS, Lopes G \& Bazotte RB (1994). Effect of combined administration of counterregulatory hormones during insulin-induced hypoglycemia in rats: lipolysis mediated by a ß-adrenergic mechanism contributes to hyperglycemia. Brazilian J ournal of Medical and Biological Research, 27: 2883-2887.

24. Souza HM, Hell NS, Lopes G \& Bazotte RB (1996). Synergistic effect of counterregulatory hormones during insulin-induced hypoglycemia in rats: participation of lipolysis and gluconeogenesis to hyperglycemia. Acta Pharmacologica Sinica, 17: 455-459.

25. Vardanega-Peicher M, Lopes G, Lima FB, Curi R, Nakano LC \& Bazotte RB (2000). Time sequence of changes in the responsiveness of glycogen breakdown to adrenergic agonists in perfused livers of rats with insulin-induced hypoglycemia. Brazilian J ournal of Medical and Biological Research, 33: 805-813.

26. Bergmeyer HU \& Bernt E (1974). Determination of glucose with glucose-oxidase and peroxidase. In: Bergmeyer HU (Editor), Methods of Enzymatic Analysis. Vol. 2. Academic Press, New York, 1205-1215.

27. Wieland O (1974). Glycerol UV-method. In: Bergmeyer HU (Editor), Methods of Enzymatic Analysis. Vol. 2. Academic Press, New York, 1405-1408.

28. Williamson DH (1974). Determination with alanine dehydrogenase. In: Bergmeyer HU (Editor), Methods of Enzymatic Analysis. Vol. 2. Academic Press, New
York, 1679-1682.

29. Lund $P$ (1974). Determination with glutaminase and glutamate dehydrogenase. In: Bergmeyer HU (Editor), Methods of Enzymatic Analysis. Vol. 2. Academic Press, New York, 1719-1722.

30. Gutmann I \& Wahlefeld W (1974). L-(+)Lactate. Determination with lactate dehydrogenase and NAD. In: Bergmeyer HU (Editor), Methods of Enzymatic Analysis. Vol. 2. Academic Press, New York, 14641472.

31. Czok R \& Lamprecht W (1974). Pyruvate, phosphoenolpyruvate and D-glycerate-2phosphate. In: Bergmeyer HU (Editor), Methods of Enzymatic Analysis. Vol. 2. Academic Press, New York, 1446-1448.

32. Gutmann I \& Bergmeyer HU (1974). Determination of urea, indicator reaction with phenol and hypochlorite. In: Bergmeyer HU (Editor), Methods of Enzymatic Analysis. Vol. 2. Academic Press, New York, 1790-1798.

33. Lager I (1991). The insulin-antagonistic effect of the counterregulatory hormones. J ournal of Internal Medicine, 229: 41-47.

34. J ahoor F, Klein S \& Wolfe R (1992). Mechanism of regulation of glucose production by lipolysis in humans. American J ournal of Physiology, 262: E353-E358.

35. Dekker $E$, Hellerstein MK, Romijn J A, Neese RA, Peshu N, Endert E, Marsh K \& Sauerwein HP (1997). Glucose homeostasis in children with falciparum malaria: precursor supply limits gluconeogenesis and glucose production. J ournal of Clinical Endocrinology and Metabolism, 82: 2514-2521.

36. Häussinger D, Weiss L \& Sies H (1975). Activation of pyruvate dehydrogenase during metabolism of ammonium ions in haemoglobin-free perfused rat liver. European J ournal of Biochemistry, 52: 421431.

37. Häussinger D \& Sies H (1979). Hepatic glutamine metabolism under the influence of the portal ammonia concentration in the perfused rat liver. European J ournal of Biochemistry, 101: 179-184. 